\title{
Research on Risk Allocation Model in PPP Projects Based on Stakeholder Network
}

\author{
Tengteng Yan 1, a, Chuan Chen ${ }^{1, b}$, Guanghua $\mathrm{Li}^{2, \mathrm{c}}$ \\ ${ }^{1}$ Business School, Sichuan University, Chengdu 610000, China \\ ${ }^{2}$ College of environment and civil engineering, Chengdu University of Technology, Chengdu \\ 610000, China \\ aytt19941128@foxmail.com, bchenchuan@scu.edu.cn , cliguanghua13@cdut.edu.cn
}

Keywords: PPP, Risk Allocation, Stakeholder Network, FAHP.

\begin{abstract}
The PPP project involves more stakeholders. Reasonable risk allocation in PPP projects is important for project performance management, which is a critical driving factor satisfying value for money. This paper aims first to identify involved stakeholders and multiple relationships and then to build a stakeholder network. Based on stakeholder network, this paper develops fuzzy analytical hierarchy process (FAHP) models for modelling risk allocation decision-making process in Public-Private Partnership projects.
\end{abstract}

\section{Introduction}

Infrastructure is one of the most active markets for PPP in China with higher capital consumption. Public-Private-Partnerships (PPP) model is a long-term cooperation relation established in infrastructure and public service sectors. Risk transfer is one of the biggest driving forces for VFM [1]. The main stakeholders involved in the PPP project is government, private capital, financing party, contractor, raw material supplier, professional operator, insurance company and professional organization. Market stakeholders are concerned that the optimal risk allocation should be assigned to the most appropriate party, not being followed [2]. The existing literature shows that the public sector and the private sector do not share a set of benefits, objectives and expectations [3]. Some empirical studies confirm that different partners' perceptions of risk, the motivations and behavior of rival partners in the risk allocation negotiations have produced significant complexity, which will undermine the success of the PPP project [4]. The uncertainty of the role of each potential risk source, in particular the private sector, how attractive risk factors affect the attractiveness of a particular project investment, and how public sector perceive risk [5].

\section{The Construction of Stakeholder Network}

Based on the research on the project stakeholders' identification, this paper uses the statistical analysis of the literature to summarize the PPP project stakeholders in China [7]. Project is a work with phased features. At different stages of the project, not only the attributes and characteristics of the project will change, the subject of the project will also play a different role with different skills [8]. This paper divides the whole process of PPP project into three stages: project decision stage, construction stage and operation stage. This article eventually obtained 13 categories of PPP project key stakeholders shown in table1. 
Table 1. Identification of key stakeholders in PPP projects

\begin{tabular}{|c|c|c|c|}
\hline Number & Stakeholder & Relationship with PPP project & Participation stage \\
\hline 1 & Local Government & Provide concessions for the project company, and ultimately may own a project & Full-life cycle \\
\hline 2 & Private Investor & Major shareholders of the project company & Full-life cycle \\
\hline 3 & Government Implementing Agency & Project planning, approval and full life cycle supervision & Full-life cycle \\
\hline 4 & Project Company & Project construction and operation unit & Construction stage and Operation stage \\
\hline 5 & Banking and Financial Institutions & Project creditor & Construction stage and Operation stage \\
\hline 6 & Contractor & Direct construction implementer & Construction stage \\
\hline 7 & Operator & Provide operational services & Operation stage \\
\hline 8 & Supplier & Provide production factor & Construction stage and Operation stage \\
\hline 9 & Prospecting and design unit & Project design and technology transformation & Decision stage and Construction stage \\
\hline 10 & Consultancy & Give advice and guide project decision & Decision stage and Construction stage \\
\hline 11 & End User & Project direct users & Operation stage \\
\hline 12 & Public & The project may have an impact on the public's production and life & Full-life cycle \\
\hline 13 & Insurance Company & Provide insurance for the project and project company & Construction stage and Operation stage \\
\hline
\end{tabular}

Project stakeholders act as a link to encourage and constrain behavior, and contractual relationship constitutes the institutional basis of project governance. Based on the identification in table 1, this paper constructs the key stakeholder network in PPP project management according to the contract relation, so as to analyze the structural characteristics of each stakeholder in the project process, as shown in Fig 1 .

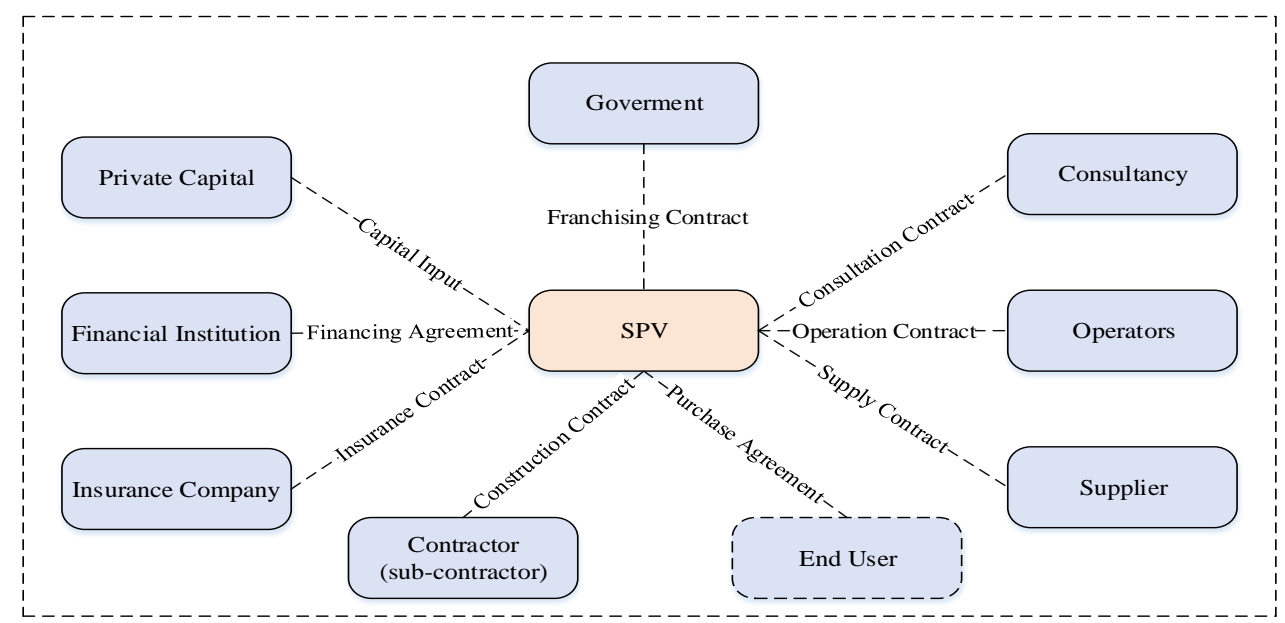

Fig. 1 Key Stakeholder Network in PPP Project

\section{The Improved Method on Risk Allocation}

\subsection{Index system construction}

There are many factors and principles affecting the risk allocation based on the stakeholder network. Combined with the factors and principles affecting the risk allocation, this paper builds a two-level risk allocation evaluation index system in Fig 2. 


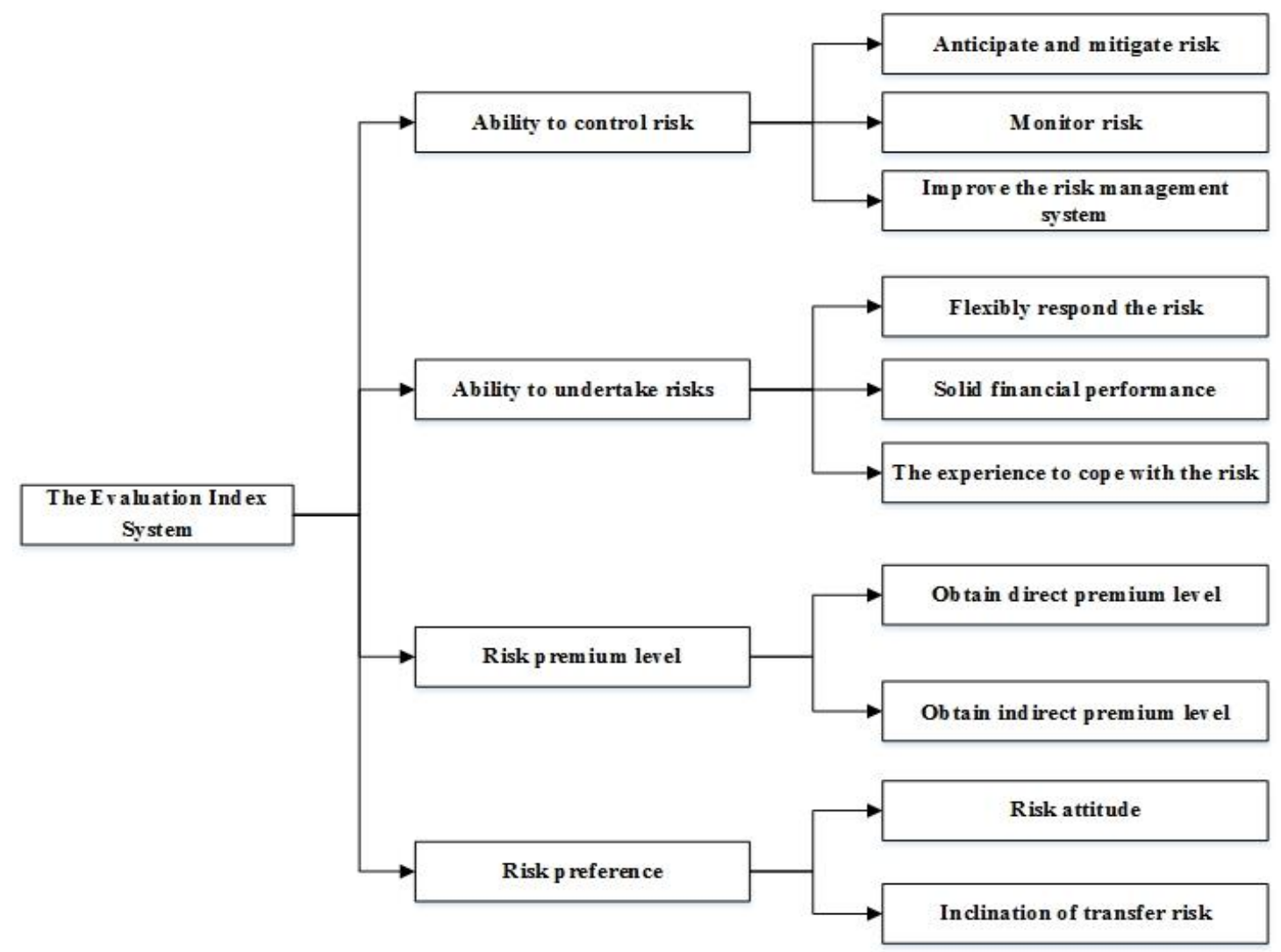

Fig. 2 The Evaluation Index System

\subsection{The determination of risk allocation ratio under each indicator}

In order to avoid the subjectivity of the results, this section introduces the method of calculating the weight of the analytic hierarchy process to determine the proportion of risk allocation under each index.

Construct a comparison matrix

Table 2 Comparison matrix under the second-level indexes

\begin{tabular}{ccccc}
\hline Second-level index $\mathrm{I}_{\mathrm{ij}}$ & Stakeholder $\mathrm{S}_{1}$ & Stakeholder $\mathrm{S}_{2}$ & $\ldots$ & Stakeholder $\mathrm{S}_{\mathrm{n}}$ \\
\hline Stakeholder $\mathrm{S}_{1}$ & 1 & $\mathrm{a}_{12}$ & $\ldots$ & $\mathrm{a}_{\mathrm{n}}$ \\
Stakeholder $\mathrm{S}_{2}$ & $1 / \mathrm{a}_{12}$ & 1 & $\ldots$ & $\mathrm{a}_{2 \mathrm{n}}$ \\
$\ldots$ & $\ldots$ & $\ldots$ & 1 & $\ldots$ \\
Stakeholder $\mathrm{S}_{\mathrm{n}}$ & $1 / \mathrm{a}_{1 \mathrm{n}}$ & $1 / \mathrm{a}_{2 \mathrm{n}}$ & $\ldots$ & 1 \\
\hline
\end{tabular}

Calculate the allocation ratio matrix of each stakeholder

$$
p_{i}=\frac{\sum_{j-1}^{n} \frac{r_{i j}}{\sum_{i-1}^{n} r_{i j}}}{\sum_{i-1}^{n} \sum_{j-1}^{n} \frac{r_{i j}}{\sum_{i-1}^{n} r_{i j}}}(i=1,2,3 \ldots, \mathrm{n}, \mathrm{j}=1,2,3 \ldots, \mathrm{n}) \quad \mathrm{P}_{i}=\left[p_{1}, p_{2}, p_{3} \ldots . p_{n}\right](i=1,2,3 \ldots, \mathrm{n})
$$

Consistency check

Calculate the consistency index $C I=\left(\lambda_{\max }-n\right) /(n-1) \cdot \lambda_{\max }$ is the maximum eigenvalue. Calculate the consistency ratio $C R=C I / R I$. If $\mathrm{CR}<0.1$, the calculated results will be valid. Otherwise, it need to be recalculated.

Calculate the comprehensive result

$$
P=\left[P_{1}^{T}, P_{2}^{T} \ldots P_{m}^{T}\right]_{\mathrm{n} \times \mathrm{m}}
$$




\subsection{Calculate the weight of the indicator}

Considering the subjectivity of expert evaluation system, this paper adopts the analytic hierarchy process (AHP) to determine the subjective weight matrix $W_{1}=\left[W_{11}, W_{12} \ldots W_{1 m}\right]$.

Table 3. The evaluation of index weight

\begin{tabular}{|c|c|c|c|c|}
\hline & Index $\mathrm{I}_{1}$ & IndexI $_{2}$ & $\ldots$ & Index $\mathrm{I}_{\mathrm{m}}$ \\
\hline Index $\mathrm{I}_{1}$ & 1 & $\mathrm{r}_{12}$ & $\ldots$ & $\mathrm{r}_{1 \mathrm{~m}}$ \\
\hline Index $\mathrm{I}_{2}$ & $1 / r_{12}$ & 1 & $\ldots$ & $\mathrm{r}_{2 \mathrm{~m}}$ \\
\hline$\ldots$ & $\ldots$ & $\ldots$ & 1 & $\ldots$ \\
\hline Index $\mathrm{I}_{\mathrm{m}}$ & $1 / \mathrm{r}_{1 \mathrm{~m}}$ & $1 / r_{2 m}$ & $\ldots$ & 1 \\
\hline
\end{tabular}

\subsection{Calculate the risk-allocation ratio of each stakeholder}

Combine the above model steps, the risk-allocation ratio matrix of each stakeholder $S=P \bullet W^{T}=\left[S_{1}, S_{2} \ldots, \mathrm{S}_{n}\right]$

\section{Conclusion}

Risk allocation is the key factor to ensure the success of infrastructure PPP projects, this paper explores the complex stakeholder network to reveal the complex game relation between stakeholders and the relations mechanism. In addition, this paper builds the allocation model based on fuzzy comprehensive evaluation and analytic hierarchy process, which can lead to theoretical innovation about risk control technology and a better understanding of the dynamic risk management in PPP projects. It is also expected that the research can generate practical implications and a decision support tool to implement risk control analysis under the stakeholder network in PPP projects. Due to the lack of empirical data, this paper has not yet validated the applicability of the model, nor does it construct dynamic model combining the changes in the life cycle of the PPP project, which will be reflected in the further research.

\section{Acknowledgments}

Completion of this paper is attributed to the financial support from the National Natural Science Foundation of China (NSFC) under the project No. 71371131.

\section{References}

[1]. Chen C, Chen P, Wang Q. Comparing the Efficiency of Public-Private Partnerships with the Traditional Procurement: Based on the Chengdu No. 6 Water Plant B[C]//Proceedings of the Tenth International Conference on Management Science and Engineering Management. Springer Singapore, 2017: 487-501.

[2]. Chung D, Hensher D A, Rose J M. Toward the betterment of risk allocation: Investigating risk perceptions of Australian stakeholder groups to public-private-partnership toll road projects [J]. Research in Transportation Economics, 2010, 30(1): 43-58.

[3]. Bing L, Akintoye A, Edwards P J, et al. The allocation of risk in PPP/PFI construction projects in the UK [J]. International Journal of project management, 2005, 23(1): 25-35.

[4]. Chung D, Hensher D A. Modelling risk perceptions of stakeholders in public-private partnership toll road contracts [J]. Abacus, 2015, 51(3): 437-483.

[5]. De Schepper S, Dooms M, Haezendonck E. Stakeholder dynamics and responsibilities in Public-Private Partnerships: A mixed experience [J]. International Journal of Project Management, 2014, 32(7): 1210-1222. 
[6]. Valipour A, Yahaya N, Md Noor N, et al. A fuzzy analytic network process method for risk prioritization in freeway PPP projects: an Iranian case study [J]. Journal of Civil Engineering and Management, 2015, 21(7): 933-947.

[7]. Babatunde S O, Perera S, Zhou L. Methodology for developing capability maturity levels for PPP stakeholder organisations using critical success factors [J]. Construction Innovation, 2016, 16(1): 81-110.

[8]. Xu Y, Yeung J F Y, Chan A P C, et al. Developing a risk assessment model for PPP projects in China-A fuzzy synthetic evaluation approach[J]. Automation in Construction, 2010, 19(7): 929-943. 